Fixed Point Theory, 20(2019), No. 2, 683-702

DOI: $10.24193 /$ fpt-ro.2019.2.45

http://www.math.ubbcluj.ro/ nodeacj/sfptcj.html

\title{
MODIFIED INERTIAL METHODS FOR FINDING COMMON SOLUTIONS TO VARIATIONAL INEQUALITY PROBLEMS
}

\author{
YEKINI SHEHU*, OLANIYI S. IYIOLA** AND EMMANUEL AKALIGWO*** \\ *University of Nigeria, Department of Mathematics, Nsukka, Nigeria \\ E-mail: yekini.shehu@unn.edu.ng \\ ** Department of Mathematics, Minnesota State University-Moorhead, Minnesota, USA \\ E-mail: olaniyi.iyiola@mnstate.edu \\ *** University of Nigeria, Department of Mathematics, Nsukka, Nigeria \\ E-mail: emmanuel.akaligwo.pg77299@unn.edu.ng
}

\begin{abstract}
It is our aim in this paper to propose modified inertial versions of both subgradient extragradient method and the extragradient method for solving common solutions to variational inequality problems involving monotone and Lipschitz continuous operators and obtain weak convergence results in real Hilbert spaces. We give several numerical illustrations of our proposed methods and give numerical comparisons of our methods with subgradient extragradient and extragradient methods.

Key Words and Phrases: Variational inequality, monotone operator, inertial terms, weak convergence, Hilbert spaces.
\end{abstract}

2010 Mathematics Subject Classification: 47H06, 47H09, 47J05, 47J25.

\section{REFERENCES}

[1] F. Alvarez, Weak convergence of a relaxed and inertial hybrid projection-proximal point algorithm for maximal monotone operators in Hilbert space, SIAM J. Optim., 14(2004), 773-782.

[2] R.Y. Apostol, A.A. Grynenko, V. V. Semenov, Iterative algorithms for monotone bilevel variational inequalities, J. Comput. Appl. Math., 107(2012), 3-14.

[3] J.-P. Aubin, I. Ekeland, Applied Nonlinear Analysis, Wiley, New York, 1984.

[4] C. Baiocchi, A. Capelo, Variational and Quasivariational Inequalities; Applications to Free Boundary Problems, Wiley, New York, 1984.

[5] H.H. Bauschke, P.L. Combettes, Convex Analysis and Monotone Operator Theory in Hilbert Spaces, CMS Books in Mathematics, Springer, New York, 2011.

[6] R.S. Burachik, A.N. Iusem, B.F. Svaiter, Enlargement of monotone operators with applications to variational inequalities, Set-Valued Anal., 5(1997), 159-180.

[7] G. Cai, Y. Shehu, O.S. Iyiola, Strong convergence results for variational inequalities and fixed point problems using modified viscosity implicit rules, Numer. Algor., DOI 10.1007/s11075-0170327-8.

[8] A. Cegielski, Iterative Methods for Fixed Point Problems in Hilbert Spaces, Lecture Notes in Mathematics 2057, Springer, Berlin, 2012.

[9] Y. Censor, A. Gibali, S. Reich, Strong convergence of subgradient extragradient methods for the variational inequality problem in Hilbert space, Optim. Methods Softw., 26(2011), 827-845. 
[10] Y. Censor, A. Gibali, S. Reich, The subgradient extragradient method for solving variational inequalities in Hilbert space, J. Optim. Theory Appl., 148(2011), 318-335.

[11] Y. Censor, A. Gibali, S. Reich, S. Sabach, Common Solutions to Variational Inequalities, SetValued Anal., 20(2012), 229-247.

[12] Q.L. Dong, Y.Y. Lu, J. Yang, The extragradient algorithm with inertial effects for solving the variational inequality, Optimization, 65(2016), 2217-2226.

[13] Q.L. Dong, H.B. Yuan, Y.J. Cho, Th. M. Rassias, Modified inertial Mann algorithm and inertial CQ-algorithm for nonexpansive mappings, Optim. Lett., DOI 10.1007/s11590-016-1102-91-16.

[14] F. Facchinei, J.-S. Pang, Finite-Dimensional Variational Inequalities and Complementarity Problems, Vol. II, Springer Series in Operations Research, Springer, New York, 2003.

[15] R. Glowinski, J.-L. Lions, R. Trémolières, Numerical Analysis of Variational Inequalities, NorthHolland, Amsterdam, 1981.

[16] B.-S. He, Z.-H. Yang, X.-M. Yuan, An approximate proximal-extragradient type method for monotone variational inequalities, J. Math. Anal. Appl., 300(2004), 362-374.

[17] D.V. Hieu, Parallel and cyclic hybrid subgradient extragradient methods for variational inequalities, Afrika Math., 28(2017), 677-692.

[18] D.V. Hieu, P.K. Anh, L.D. Muu, Modified hybrid projection methods for finding common solutions to variational inequality problems, Comput. Optim. Appl., 66(2017), 75-96.

[19] A.N. Iusem, M. Nasri, Korpelevich's method for variational inequality problems in Banach spaces, J. Global. Optim., 50(2011), 59-76.

[20] A.N. Iusem, B.F. Svaiter, A variant of Korpelevich's method for variational inequalities with a new search strategy, Optimization, 42(1997), 309-321.

[21] D. Kinderlehrer, G. Stampacchia, An Introduction to Variational Inequalities and Their Applications, Academic Press, New York, 1980.

[22] I.V. Konnov, Combined Relaxation Methods for Variational Inequalities, Springer-Verlag, Berlin, 2001.

[23] G.M. Korpelevich, The extragradient method for finding saddle points and other problems, Ekonomika i Mat. Metody, 12(1976), 747-756.

[24] N. Nadezhkina, W. Takahashi, Strong convergence theorem by a hybrid method for nonexpansive mappings and Lipschitz-continuous monotone mappings, SIAM J. Optim., 16(2006), 1230-1241.

[25] Y. Shehu, O.S. Iyiola, Strong convergence result for monotone variational inequalities, Numer. Algor., 76(2017), 259-282.

[26] Y. Shehu, O.S. Iyiola, Iterative algorithms for solving fixed point problems and variational inequalities with uniformly continuous monotone operators, Numer. Algor., DOI: 10.1007/s11075017-0449-z

[27] M.V. Solodov, B.F. Svaiter, A new projection method for variational inequality problems, SIAM J. Control Optim., 37(1999), 765-776.

[28] P. Tseng, A modified forward-backward splitting method for maximal monotone mappings, SIAM J. Control Optim., 38(2000), 431-446.

[29] H. Yamada, The hybrid steepest descent method for the variational inequality problem over the intersection of fixed point sets of nonexpansive mappings, In: Butnariu D, Censor Y, Reich $S$, editors. Inherently parallel algorithms in feasibility and optimization and their applications, Studies in Computational Mathematics, Amsterdam: North-Holland; 2001. p. 473-504.

Received: June 7, 2017; Accepted: December 15, $201 \%$. 
